\title{
BMJ Open Multimorbidity in Children and Youth Across the Life-course (MY LIFE): protocol of a Canadian prospective study
}

\author{
Mark A Ferro, ${ }^{1}$ Ellen L Lipman, ${ }^{2}$ Ryan J Van Lieshout, ${ }^{2}$ Jan Willem Gorter, ${ }^{3}$ \\ Lilly Shanahan, ${ }^{4}$ Michael Boyle, ${ }^{2}$ Kathy Georgiades, ${ }^{2}$ Brian Timmons ${ }^{2}$
}

To cite: Ferro MA, Lipman EL, Van Lieshout RJ, et al. Multimorbidity in Children and Youth Across the Life-course (MY LIFE): protocol of a Canadian prospective study. BMJ Open 2019;9:e034544. doi:10.1136/ bmjopen-2019-034544

- Prepublication history for this paper is available online. To view these files, please visit the journal online (http://dx.doi org/10.1136/bmjopen-2019034544)

Received 24 September 2019 Revised 02 October 2019 Accepted 03 October 2019

Check for updates

(c) Author(s) (or their employer(s)) 2019. Re-use permitted under CC BY-NC. No commercial re-use. See rights and permissions. Published by BMJ.

${ }^{1}$ School of Public Health and Health Systems, University of Waterloo, Waterloo, Ontario,

Canada

${ }^{2}$ Department of Psychiatry and Behavioural Neurosciences,

McMaster University, Hamilton,

Ontario, Canada

${ }^{3}$ Department of Pediatrics, McMaster University, Hamilton, Ontario, Canada

${ }^{4}$ Department of Psychology, University of Zurich, Zurich, Switzerland

Correspondence to

Dr Mark A Ferro;

mark.ferro@uwaterloo.ca

\section{ABSTRACT}

Introduction Multimorbidity, the co-occurrence of a chronic physical condition and mental disorder, affects a substantial number of children and youth and can lead to compromised quality of life, hardship for families, and an increased burden on the healthcare system. We are conducting a study to document the course of mental disorder in children and youth diagnosed with a chronic physical condition; identify predictors of child and youth multimorbidity; examine whether the effects of these predictors are moderated by relevant psychosocial and biological factors; explore potential inflammatory and stress biomarkers that mediate the onset of child and youth multimorbidity; and, assess whether multimorbidity in children and youth alters patterns of mental health service use.

Methods and analysis Multimorbidity in Children and Youth Across the Life-course (MY LIFE) is a prospective study. Two hundred and fifty children and youth aged 2-16 years diagnosed with a chronic physical condition along with one parent will be recruited from the outpatient clinics at a paediatric tertiary care centre. Data will be collected using a multi-informant, multimethod design at four time-points (at recruitment, and at 6,12 and 24 months postrecruitment). Parents will provide reports for all children/youth. In addition, youth $\geq 10$ years will self-report. Mental disorder will be assessed using structured interviews. On completion of data collection, participant-reported data will be linked to provincial health records to identify mental health services use. Multilevel analyses (survival, proportional hazard, structural equation modelling) will be used to address MY LIFE objectives.

Ethics and dissemination This study has been approved by the University of Waterloo Human Research Ethics Board and the Hamilton Integrated Research Ethics Board. Findings will be disseminated to key stakeholders using a number of outlets (peer-reviewed publications and conferences, lay informational pamphlets, social media).

\section{INTRODUCTION}

Children and youth with chronic physical conditions face considerable psychosocial and emotional burden due to their health challenges. ${ }^{1}$ Thus far, research that comprehensively examines child and youth multimorbidity-the co-occurrence of physical and mental disorder-is limited, including

\section{Strengths and limitations of this study}

- Unlike previous studies on child and youth multimorbidity, this is a prospective study that uses a multilevel, multimethod and multi-informant approach.

- Multimorbidity in Children and Youth Across the Lifecourse aims to determine biological and psychosocial processes by which some children and youth develop multimorbidity whereas others do not; this is essential for establishing effective interventions.

- Findings have the potential to support children/youth and families, improve care and reduce health system costs.

- Recruitment from a single paediatric tertiary care centre might reduce generalisability of findings.

- As with all prospective studies, missing data and attrition may be problematic; however, multiple approaches will be used to minimise sample loss and other biases.

research on the mechanisms involved in the onset and outcomes of multimorbidity.

Yet, understanding child and youth multimorbidity is an urgent public health problem. Improvements in healthcare have reduced childhood mortality, but many surviving children grow up into adulthood. ${ }^{2}$ Furthermore, because most adult mental disorders have their onset in childhood or adolescence, ${ }^{3}$ the onset of multimorbidity likely typically occurs early in life, with long-term consequences for children and youth, their families, the healthcare system and society. Indeed, cost calculations suggest that a small proportion of children (approximately 5\%, often multimorbid) account for nearly $60 \%$ of healthcare costs for individuals $<18$ years of age. ${ }^{4}$ Taken together, multimorbidity and its sequelae are an important public health concern. ${ }^{56}$

Current research on child and youth multimorbidity suggests that its prevalence is high. ${ }^{7}$ Population-based studies report prevalence estimates of $20 \%-30 \%,{ }^{8-10}$ clinical studies $\geq 50 \%{ }^{11}{ }^{12}$ Most extant studies report that multimorbidity has a negative impact on 
the quality of life of young people ${ }^{111^{13-15}}$ (for an exception see Ferro et al. ${ }^{16}$ Impact on the family environment appears more mixed, with some studies reporting closer parent-child relationships in those with (vs without) multimorbidity. ${ }^{16}{ }^{17}$ Studies on family sociodemographic correlates of multimorbidity are rare, with one study reporting no association. ${ }^{11}$ Emerging evidence implicates biological mechanisms that link physical and mental disorder, including immunological, inflammatory and stress-related mechanisms. ${ }^{18-20}$ Findings regarding mental health services use among children and youth with multimorbidity are also mixed; clinical studies reporting less use of acute mental health services, whereas population studies reporting more overall and acute mental health services use. ${ }^{1621}$ Despite this nascent literature on child and youth multimorbidity, many important gaps in knowledge remain. The Multimorbidity in Children and Youth Across the Life-course (MY LIFE) study was developed to address these gaps.

First, studies of clinical samples of children and youth with physical conditions are typically small and crosssectional. ${ }^{1122} 23$ The lack of prospective studies limits our ability to: (1) understand the temporality of effects; (2) document the natural course of multimorbidity over time; (3) calculate incidence rates; (4) generalise findings to the broader population of children and youth with multimorbidity. MY LIFE will recruit a larger sample of children and youth with a variety of physical conditions and follow them and their families prospectively on multiple measurement occasions. This will inform opportunities for prevention/intervention at all levels: primary (preventing onset of mental comorbidity), secondary (reducing symptoms in children and youth with subclinical symptomatology) and tertiary (improving function in children and youth with multimorbidity). With regards to generalisability, few studies (all using population samples) have compared mental disorder across physical conditions. ${ }^{8425}$ While findings typically show negligible differences across conditions, ${ }^{26}{ }^{27}$ identifying conditionspecific associations may be useful in understanding mechanisms underlying the onset of multimorbidity and informing intervention.

Second, previous studies have typically assessed symptoms of emotional or behavioural problems and not mental disorder, per se. ${ }^{122728}$ This is relevant given recent evidence that assessment type moderates estimates of association between physical conditions and mental disorder and influences estimates of prevalence in child and youth populations. ${ }^{72}$ Furthermore, there is robust evidence that agreement on measures of mental and psychosocial health between parent and child/youth reports are low. ${ }^{11} 3031$ Combined, these methodological limitations can bias estimates (via misclassification), which ultimately could misdirect resources for appropriate mental healthcare for children and youth. MY LIFE will implement a multimethod and multi-informant approach to measuring child and youth mental health and related psychosocial outcomes.
Third, little is known about the mechanisms that underlie the development of multimorbidity in children and youth. There has been some work highlighting biological $^{18} 19$ and psychosocial mechanisms ${ }^{32}$ independently, but few investigations have sought to combine these approaches to provide a more comprehensive understanding of this phenomenon. One study has demonstrated that maternal depression has direct effects on immunological and stress regulation in mothers and their children, which subsequently influences symptoms of mental disorder in children. ${ }^{20}$ However, that study did not examine these mechanisms in the context of children having a physical condition. Recent evidence in this vulnerable population not only shows a confluence of biological and psychosocial pathways linking physical and mental health, ${ }^{34}$ but that effects may be different for male and female children. ${ }^{36}$ Relatedly, there is robust evidence demonstrating the positive effect of physical activity and exercise on the mental health of, ${ }^{37-41}$ as well as reducing levels of inflammatory markers in, children and youth. ${ }^{42-44}$ MY LIFE will measure physical activity and inflammatory and stress markers not previously assessed in studies of child and youth multimorbidity in an effort to more fully understand its onset and progression. Clarifying the extent to which biomarkers and psychosocial factors, and ultimately physical and mental health, change over time can inform targets for intervention to reduce risk for multimorbidity.

Fourth, use of mental healthcare has increased dramatically for children and youth in recent years, ${ }^{45}$ but knowledge as to whether multimorbidity influences service use or help-seeking behaviour is limited. The few studies that exist have reported inconsistent findings: a population study found increased mental healthcare use among youth with a physical condition and bipolar disorder, ${ }^{21}$ whereas a clinical study found that youth with multimorbidity were less likely to receive inpatient mental healthcare and had shorter hospital stays. ${ }^{16}$ Through data linkage activities with administrative health records, MY LIFE will contribute to the field by identifying how children and youth with multimorbidity access and use mental health services. Understanding the patterns of mental healthcare for children and youth with multimorbidity will provide useful information to support families navigating the health system and the evidence required to implement models of integrated physical and mental healthcare.

Overall, MY LIFE aims to: (1) document the course of mental disorder in children and youth diagnosed with a chronic physical condition; (2) identify predictors of child and youth multimorbidity; (3) examine whether the effects of these predictors are amplified or moderated by relevant psychosocial and biological factors; (4) explore potential inflammatory and stress biomarkers that mediate the onset of child and youth multimorbidity; (5) assess the extent to which child and youth multimorbidity alters patterns of mental health service use. 


\section{METHODS}

\section{Design}

The design of MY LIFE was informed by our pilot study. ${ }^{11}$ MY LIFE is a prospective study in which children and youth with chronic physical conditions and their primary caregiving parent/guardian will be recruited from outpatient programmes at a paediatric hospital in Canada. Participants will be followed for 24 months, with assessments at four occasions: recruitment (baseline) and 6, 12 and 24 months. On completion of the in-person data collection, participant-reported data will be linked to provincial health records to document use of mental health services.

\section{Participants}

Children and youth aged 2-16 years with one chronic physical condition is the population of interest. Physiciandiagnosed physical conditions are those expected to last $\geq 12$ months; and result in $\geq 1$ of the following sequelaefunctional limitations, dependencies to compensate for limitations and need for additional healthcare. ${ }^{46}$

Children and youth with multiple physical conditions (ie, medically complex) at the time of recruitment will be excluded as these children/youth represent a small subgroup within this population and whose outcomes and healthcare use are established. ${ }^{47-49}$ Associations with mental comorbidity in these children and youth is likely different compared with children and youth who suffer from one, physical condition only. Also, children/youth and parents with insufficient English language skills will be excluded, because the selected measures have not been validated in other languages.

Multimorbidity is evenly distributed across age and sex. ${ }^{10}$ Thus, we expect to recruit males and females in a 1:1 ratio, evenly distributed across ages. Our age range is broad to increase coverage and generalisability. We will include children and youth who, as a function of their physical condition, have a developmental or learning disability (eg, in certain presentations of epilepsy). For these children/youth, we will rely on parent reports only.

\section{Procedures}

Study procedures are outlined in figure 1. Participants will be recruited from the dermatology, endocrinology, gastroenterology, haemophilia, immunology, neurology, respirology and rheumatology programmes. Research assistants (RAs) will work in tandem with health professionals to help identify eligible families. Clinic nurses will introduce the study to families and invite them to speak with the RA either before or after their medical appointment. The RA will verify eligibility, describe the study and obtain written permission from eligible participants to be contacted a few days later.

The study coordinator will then contact parents to schedule a time for participants to complete the structured interviews and biological sample collections at

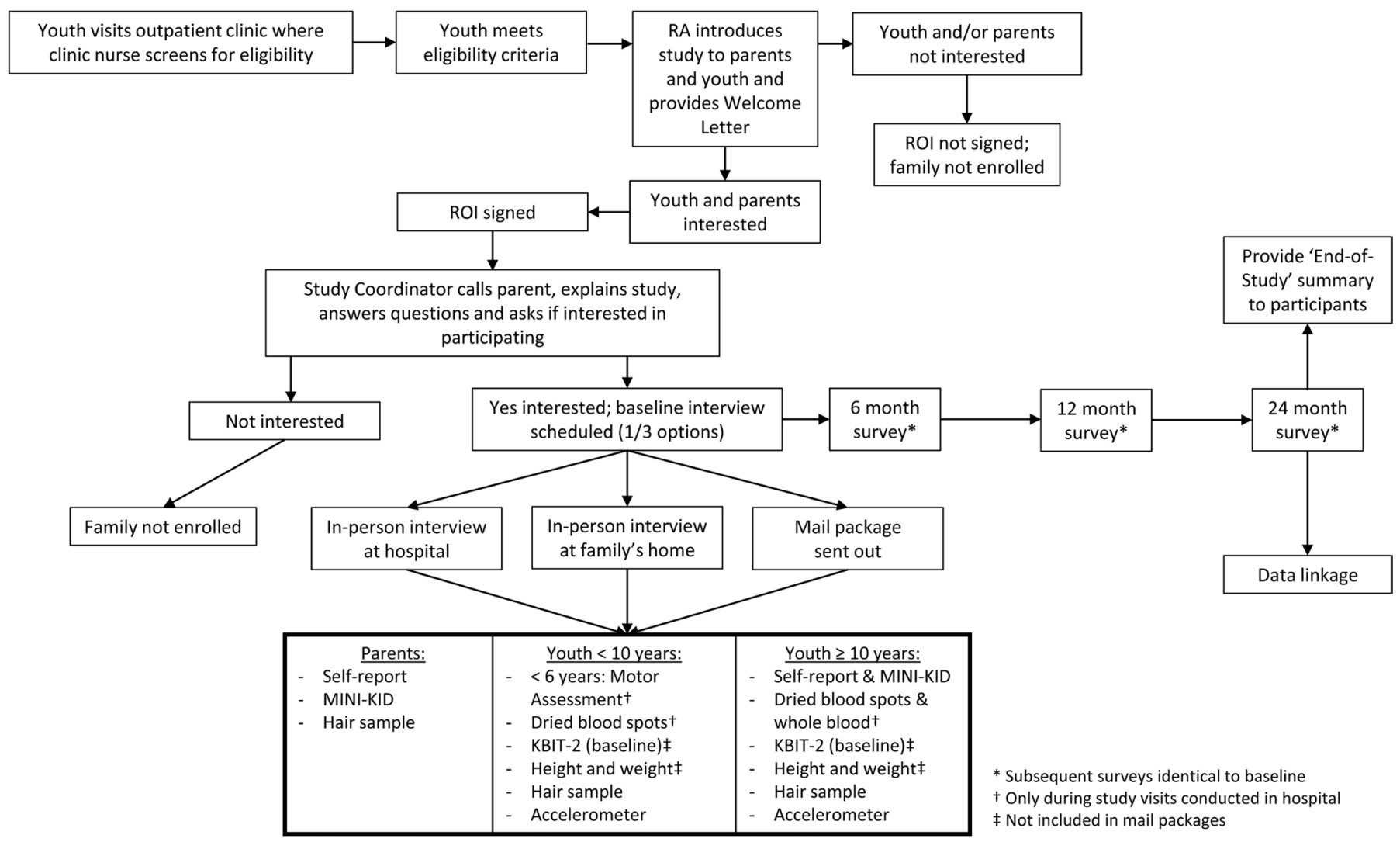

Figure 1 Multimorbidity in Children and Youth Across the Life-course study flowchart. KBIT-2, Kaufman Brief Intelligence Test, second edition; MINI-KID, Mini International Neuropsychiatric Interview for Children and Adolescents; RA, research assistant; $\mathrm{ROI}$, release of information. 
the hospital. Alternatively, the RA may meet with participants at their home to accommodate travel or child care schedules. In the rare case that a family is not able to meet in-person (either at the hospital or in their home), packages will be mailed, followed by telephone calls from the study coordinator with reminders for completion. During study visits at the hospital, the RA will meet with participants in a private research office. Informed written consent (parent and youth aged 16 years) and assent (children and youth aged $7-15$ years) will be obtained at the beginning of the first visit.

Data collection for MY LIFE is based on the following a priori consideration that assessments should be far enough apart to allow sufficient time for detectable changes to occur in measures of children and youth, family and clinical characteristics and to not burden participants. Data will be collected every 6 months during the first year given that the period close to diagnosis is a dynamic time in terms of clinical management and family adaptation, and then again 1 year later. The experience of our research team suggests that a 2-year follow-up is adequate for detecting meaningful changes in psychosocial outcomes of children and youth with physical conditions. ${ }^{33} 50$ Data will be collected using independent structured interviews and self-reported questionnaires on a laptop (computer assisted to minimise missing data) for children/youth and parents to ensure privacy. Parent reports will be collected for all participating youth; youth aged $\geq 10$ years will also provide reports. Data collection will take approximately $60-90 \mathrm{~min}$. On completion of each interview, children/youth and parents will both be provided with a $\$ 30$ gift card and if applicable, a parking voucher.

\section{Measures}

We will implement a multilevel, multimethod and multiinformant approach to data collection. Variables will be measured at the individual, family and communitylevels using child/youth and parent-report and linkage with administrative health records obtained for the study period.

\section{Self-reported measures}

We will be using two measures of child and youth mental health as our primary outcome of interest. The Mini International Neuropsychiatric Interview for Children and Adolescents (MINI-KID) is a clinical diagnostic interview designed to assess the presence of Diagnostic and Statistical Manual of Mental Disorders (DSM)-5 and International Statistical Classification of Diseases and Related Health Problems (ICD)-10 psychiatric disorders in children and youth over the past 6 months. ${ }^{52}$ We will be utilising the following modules which represent the most common mental disorders in childhood and adolescence $^{53}{ }^{54}$ : major depressive episode, separation anxiety disorder, social anxiety disorder, specific phobia, attention-deficit hyperactivity disorder, conduct disorder, oppositional defiant disorder and generalised anxiety disorder. The MINI-KID has demonstrated strong validity and reliability in population and clinical samples of children and youth. ${ }^{3055}$

Second, the Ontario Child Health Study Emotional Behavioural Scales (OCHS-EBS) are a set of self-reported checklists measuring symptoms of psychopathology over the past 6 months using a 3-point Likert scale. ${ }^{55}{ }^{56}$ Items are scored 0,1 , or 2, indicating responses of 'never or not true', 'sometimes or somewhat true' and 'often or very true', respectively. The raw scores are summed to calculate a scale score for each mental disorder (major depressive, generalised anxiety, separation anxiety, social phobia, attention-deficit hyperactivity, oppositional defiant, conduct), as well as total severity score and scores for internalising and externalising disorders. The OCHS-EBS demonstrates robust psychometric properties. ${ }^{556}$

Child/youth and parent mental health and quality of life, child/youth physical and psychosocial functioning, child/youth intelligence, family environment and sociodemographic characteristics will be assessed using psychometrically robust self-reported measures. When applicable, parents will also complete quality of life and mental health measures for a sibling within 3 years of age from the child in the study to understand the broader impact of child and youth multimorbidity on family members. Details of these measures are described in table 1 .

\section{Biological assessments}

To date, the few studies that have assessed markers of systemic inflammation suggest associations with child and youth mental health. ${ }^{5758}$ We will measure whether systematic inflammatory biomarkers (which tend to be higher in young people with physical conditions) ${ }^{59-61}$ mediate the timing of onset of multimorbidity. We will collect dried blood spots for all children and youth and whole blood for youth $\geq 10$ years at each measurement occasion. Our procedures for collecting dried blood spots by research staff have been adapted from published guidelines. ${ }^{62}$ Whole blood samples will only be collected during study interviews in hospital by experienced phlebotomists. Samples will be analysed using high-sensitivity ELISA to quantify levels of C-reactive protein, tumour necrosis factor- $\alpha$, interleukin- $1 \beta$ and interleukin- 6 , as these are robust indicators of systemic inflammation. ${ }^{62}$

Cortisol, a glucocorticoid hormone, is released by the hypothalamic-pituitary-adrenal axis in response to stress. ${ }^{63}$ Cortisol extracted from saliva, urine and blood provides transient measures of physiological stress, with limited utility for understanding chronic physiological stress in young people with chronic conditions. ${ }^{64}$ Hair cortisol concentration has recently been identified as a potentially valuable biomarker, averaging daily fluctuations in circulating cortisol levels. ${ }^{65-68}$ Hair sampling represents a non-invasive method to measure chronic physiological stress and reduces the impact of individual and contextual differences associated with circulating cortisol. ${ }^{69} 70$ Hair will be collected using a standardised 
Table 1 Study questionnaires

\begin{tabular}{|c|c|c|}
\hline Construct & Measure and description & Informant \\
\hline \multirow[t]{2}{*}{ Child/youth mental health } & $\begin{array}{l}\text { Ontario Child Health Study Emotional Behavioural Scales }{ }^{55} 56 \\
52-\text { item symptom checklist providing total, internalising and externalising scores, as well as } \\
\text { subscale scores for major depressive disorder, separation anxiety, social phobia, generalised } \\
\text { anxiety, attention-deficit hyperactivity, oppositional defiant disorder and conduct disorder }\end{array}$ & $\begin{array}{l}\text { Child/youth and } \\
\text { parent }\end{array}$ \\
\hline & $\begin{array}{l}\text { Strengths and Difficulties Questionnaire } \\
\text { 25-item checklist providing total difficulties scores, as well as domains of emotional problems, } \\
\text { conduct problems, hyperactivity, peer problems and prosocial }\end{array}$ & Parent \\
\hline $\begin{array}{l}\text { Child/youth psychosocial } \\
\text { health }\end{array}$ & $\begin{array}{l}\text { Self Description Questionnaire } 8990 \\
\text { Five items from the General Self-image subscale; adapted from the National Longitudinal Survey } \\
\text { of Children and Youth }\end{array}$ & $\begin{array}{l}\text { Child/youth and } \\
\text { parent }\end{array}$ \\
\hline Child/youth physical health & $\begin{array}{l}\text { WHO Disability Assessment Schedule } 2.0^{93} 94 \\
\text { 12-item measure of disability and functioning in the domains of cognition, mobility, self-care, }\end{array}$ & $\begin{array}{l}\text { Child/youth and } \\
\text { parent }\end{array}$ \\
\hline
\end{tabular}
getting along, life activities and participation

$\begin{array}{lll}\text { Child/youth intelligence } & \begin{array}{l}\text { Kaufman Brief Intelligence Test, second edition } \\ \text { Brief measure of verbal and non-verbal intelligence }\end{array} \\ \text { Parent mental health } & \begin{array}{l}\text { Center for Epidemiologic Studies Depression Scale }{ }^{96} \\ \text { 20-item measure of depressive symptoms across four domains depressed affect, positive affect, } \\ \text { somatic activity and interpersonal relations }\end{array}\end{array}$

\begin{tabular}{|c|c|c|}
\hline & $\begin{array}{l}\text { Generalized Anxiety Disorder }{ }^{97} \\
\text { Seven items measuring symptoms of generalised anxiety }\end{array}$ & Parent \\
\hline Parent quality of life & $\begin{array}{l}\text { Short Form- } 36^{98} \\
36 \text {-item scale that assesses eight health domains: physical functioning, bodily pain, role } \\
\text { limitations due to physical health problems, role limitations due to personal or emotional } \\
\text { problems, emotional well-being, social functioning, energy/fatigue and general health } \\
\text { perceptions, and a single item that provides an indication of perceived change in health }\end{array}$ & Parent \\
\hline \multirow[t]{3}{*}{ Family environment } & $\begin{array}{l}\text { McMaster Family Assessment Device } 99100 \\
12 \text { items comprising the General Functioning subscale measures aspects of communication, } \\
\text { problem solving, behavioural control, affective responsiveness and involvement and roles }\end{array}$ & Parent \\
\hline & $\begin{array}{l}\text { Parental Stress Scale } 101102 \\
\text { 18-item scale that includes four domains of parenting: rewards, stressors, loss of control and } \\
\text { satisfaction }\end{array}$ & Parent \\
\hline & $\begin{array}{l}\text { Sibling Inventory of Differential Experience }{ }^{103} \\
\text { 18-item scale assessing differential treatment by mother and father in relation to closest-aged } \\
\text { sibling }\end{array}$ & Child/youth \\
\hline Sociodemographics & Various items obtained from population-based surveys conducted by Statistics Canada & Parent \\
\hline
\end{tabular}

Only youth $\geq 10$ provided self-reported data.

approach by research staff from children/youth and parents by cutting approximately 80 strands (roughly $4 \mathrm{~mm}$ diameter) from the posterior vertex of the head, as close to the scalp as possible. the extraction and assaying of cortisol will follow established procedures, which we have also used previously. ${ }^{34}$ Variables hypothesised to affect hair cortisol concentration (eg, hair washes, medications, smoking behaviour (including exposure to secondhand smoke)) will be collected via parent report on a separate form. ${ }^{677172}$
While parents are completing study questionnaires, children 2-5 years will complete the Peabody Developmental Motor Scales, second edition (PDMS-2) to assess gross motor development. ${ }^{73}$ This measure, which requires $20-30 \mathrm{~min}$ to complete, is collected only at study visits conducted at the hospital. We will be using three gross motor subtestsstationary, locomotion and object manipulation-to obtain a gross motor developmental quotient. The PDMS-2 has excellent reliability and is valid for evaluating children/ youth with varying levels of gross motor skills. ${ }^{74}$ 
Habitual physical activity at each assessment will be monitored using accelerometery, providing the duration, intensity and frequency of movement among children and youth. Following standard practice, we will monitor physical activity over seven consecutive days, reflecting recent levels of physical activity. ${ }^{76}$ Activity intensity is analysed according to cut-points developed and validated specifically for this unit (ActiGraph wGT3X-BT). ${ }^{77}$ Sitting and standing height and weight will also be collected for children and youth at each assessment.

\section{Patient and public involvement}

Patients or the public were not involved in the design, or conduct, or reporting of this protocol. The role of participating families with regards to our knowledge translation strategy is described in the Ethics and dissemination section.

\section{DATA ANALYSIS AND LINKAGE \\ Sample size calculation}

Simulations that altered various parameter estimates were conducted to determine the sample size requirements for this study. ${ }^{78} 79$ Results suggested that a study with 250 children and youth and four measurement occasions would be adequately powered $(1-\beta \geq 0.80)$ at $\alpha=0.05$ to estimate non-linear changes in mental health trajectories (primary study objective), examine relevant mediating and moderating effects and explore subgroup differences (eg, by physical health or mental disorder). Assuming $40 \%$ of eligible children/youth or their parents refuse participation after being provided with details of the study, and $20 \%$ of initially enrolled children/youth do not complete the baseline assessment, we anticipate approaching approximately 520 families about the study. If appropriate, multiple imputation will be used to account for missing data.

\section{Data analysis}

Multilevel models will delineate trajectories of psychopathology and psychosocial outcomes over time, survival analysis and proportional hazard models will be used to model risk and predictors of child and youth multimorbidity, and structural equation modelling will identify factors that mediate and moderate outcomes. ${ }^{80}{ }^{81}$ Multinomial logistic regression will be used to model patterns of mental health service use for children and youth with and without multimorbidity. Additional analyses will be stratified to examine subgroup differences, including by sex, because prevalence of and pathways to mental disorder is not the same for males and females. ${ }^{538283}$ When possible, we will use age-stratified analysis based on developmental periods to address the challenge of making inferences on heterogeneous samples. The developmental periods will be early childhood (2-6 years), middle childhood/early adolescence (7-12 years) and older adolescence (13-16 years).

\section{Data linkage}

Study data will be linked using the provincial health numbers of participants with the health data collected by the Ministry of Health to obtain information on mental health service use. Databases to be linked will include the National Ambulatory Care Reporting System, Discharge Abstract Database and Ontario Health Insurance Plan. We will use postal codes to link study data with Canadian census data to measure community-level variables, such as neighbourhood income and geographic proximity to health services.

\section{DISCUSSION}

Child and youth multimorbidity creates considerable challenges for the individual, family and healthcare system. By focusing on modifiable predictors and associated health and psychosocial outcomes of child and youth multimorbidity, this study will advance knowledge of the aetiology and course of mental disorder in a large vulnerable population and refine our understanding of how child and youth multimorbidity influences interaction with the healthcare system.

We note the following challenges associated with conducting this study. First, the eligibility criteria are purposefully broad-in terms of age and physical health problems-in order to enrol a large enough sample of children and youth to address our objectives. This heterogeneity may limit the applicability of findings to specific subgroups (eg, young children, youth with juvenile arthritis). However, evidence suggests that differences in risk for mental disorder across physical conditions is negligible. ${ }^{811} 2426$ In addition, we will conduct age and condition-stratified analyses to adjust for potential residual confounding and identify potential stratumspecific findings.

Second, attrition may be problematic. Because our study includes parents and children/youth, attrition of one member of the dyad may likely result in the other being lost. To mitigate and minimise sample loss, we are oversampling, implementing a strong follow-up strategy which include multiple contacts over time, ${ }^{84}$ and using robust statistical methods to compute unbiased estimates in the presence of missing data. ${ }^{84-86}$

Third, at the time of this proposal, some mental health services were funded by the provincial Ministry of Children, Community and Social Services (MCCSS). These services are not captured in the datasets in which we will link our study data. Our previous experience has shown that linkage with MCCSS is not possible; we will overcome this challenge by directly asking parents about the MCCSS-funded mental health services they access using the methods described in population-based studies conducted by Statistics Canada.

In summary, we expect that findings from MY LIFE will lead to development and implementation of universal and targeted risk-reduction strategies to reduce mental disorder in children and youth with physical conditions and will inform initiatives for the integration of physical and mental healthcare for children and youth-potentially aiding in eliminating stigma surrounding mental health and help-seeking. Ultimately, findings from this 
study will improve the quality of life for children and youth and their families, and potentially reduce burdens on the healthcare system.

\section{ETHICS AND DISSEMINATION}

MY LIFE received ethical approval from the University of Waterloo Human Research Ethics Board (ORE-22183) and the Hamilton Integrated Research Ethics Board (2797). Dissemination of findings will target academic outlets including publication in peer-reviewed journals and presentations at national and international conferences. We will engage health professional and administrative stakeholders with presentations at departmental rounds and divisional meetings to discuss opportunities to improve child and youth health through clinical practice changes informed by findings from MY LIFE.

At the end of the study, participating families will receive a report detailing findings in a coherent, understandable format. Additionally, we will partner with families to co-produce pamphlets containing key messages from this study; what to expect postdiagnosis of a physical condition, supportive services for children and youth and families, and information about the signs and symptoms of mental disorder. Pamphlets will be distributed to clinics and community agencies, as well as websites known for their reach and impact (eg, Mental Health Commission of Canada, Centre for Addiction and Mental Health).

We will also disseminate findings to the mental health community. The principal investigator will give webinars to staff of mental health agencies and their clients which will be recorded and distributed using existing knowledge translation infrastructure. Finally, we will incorporate social media into our dissemination strategy to reach the general community through media releases, summaries on institution websites, and communicate findings via popular outlets (eg, Twitter).

\section{Twitter Mark A Ferro @ARCH_Lab and Jan Willem Gorter @Dr_Gorter}

Acknowledgements The authors gratefully acknowledge the children, parents and health professionals and their staff without whose participation MY LIFE would not be possible. We especially thank Jessica Zelman for coordinating the study.

Contributors MAF is the principal investigator of MY LIFE, having conceived the study and its design, was responsible for obtaining funding, leading its implementation, and drafting the protocol manuscript. ELL, RJVL, JWG, LS, MB, KG and BT are co-investigators of MY LIFE, having contributed to its design, obtaining funding and editing the manuscript for content. All authors approved the manuscript for publication.

Funding This work is supported by the Canadian Institutes of Health Research grant number PJT- 148602.

Competing interests None declared.

Patient consent for publication Not required.

Provenance and peer review Not commissioned; peer reviewed for ethical and funding approval prior to submission.

Open access This is an open access article distributed in accordance with the Creative Commons Attribution Non Commercial (CC BY-NC 4.0) license, which permits others to distribute, remix, adapt, build upon this work non-commercially, and license their derivative works on different terms, provided the original work is properly cited, appropriate credit is given, any changes made indicated, and the use is non-commercial. See: http://creativecommons.org/licenses/by-nc/4.0/.
REFERENCES

1 Schwartz LA, Feudtner C. Providing integrated behavioral health services to patients with serious pediatric illness. JAMA Pediatr 2019;173:817.

2 Ontario Association of Community Care Access Centres. Health comes home: a conversation about children with complex health needs (part 3). Toronto, 2013: December 2013.

3 Kessler RC, Berglund P, Demler O, et al. Lifetime prevalence and age-of-onset distributions of DSM-IV disorders in the National comorbidity survey replication. Arch Gen Psychiatry 2005;62:593-602.

4 Wodchis WP, Austin PC, Henry DA. A 3-year study of high-cost users of health care. Can Med Assoc J 2016;188:182-8.

5 Dobbie M, Mellor D. Chronic illness and its impact: considerations for psychologists. Psychol Health Med 2008;13:583-90.

6 Maslow GR, Haydon AA, Ford CA, et al. Young adult outcomes of children growing up with chronic illness: an analysis of the National longitudinal study of adolescent health. Arch Pediatr Adolesc Med 2011;165:256-61.

7 Barker MM, Beresford B, Bland M, et al. Prevalence and incidence of anxiety and depression among children, adolescents, and young adults with life-limiting conditions. JAMA Pediatr 2019;173:835.

8 Ferro MA. Major depressive disorder, suicidal behaviour, bipolar disorder, and generalised anxiety disorder among emerging adults with and without chronic health conditions. Epidemiol Psychiatr Sci 2016;25:462-74.

9 Merikangas KR, Calkins ME, Burstein M, et al. Comorbidity of physical and mental disorders in the neurodevelopmental genomics cohort study. Pediatrics 2015;135:e927-38.

10 Tegethoff M, Belardi A, Stalujanis E, et al. Association between mental disorders and physical diseases in adolescents from a nationally representative cohort. Psychosom Med 2015;77:319-32.

11 Butler A, Van Lieshout RJ, Lipman EL, et al. Mental disorder in children with physical conditions: a pilot study. BMJ Open 2018;8:e019011.

12 Canning EH, Hanser SB, Shade KA, et al. Mental disorders in chronically ill children: parent-child discrepancy and physician identification. Pediatrics 1992;90:692-6.

13 Chen $\mathrm{H}$, Cohen P, Kasen S, et al. Impact of adolescent mental disorders and physical illnesses on quality of life 17 years later. Arch Pediatr Adolesc Med 2006;160:93-9.

14 Lee SL, Cheung YF, Wong HSW, et al. Chronic health problems and health-related quality of life in Chinese children and adolescents: a population-based study in Hong Kong. BMJ Open 2013;3:e001183.

15 Waters E, Davis E, Nicolas C, et al. The impact of childhood conditions and concurrent morbidities on child health and wellbeing. Child Care Health Dev 2008;34:418-29.

16 Ferro MA, Lipman EL, Van Lieshout RJ, et al. Mental-Physical multimorbidity in youth: associations with individual, family, and health service use outcomes. Child Psychiatry Hum Dev 2019;50:400-10.

17 Chavira DA, Garland AF, Daley S, et al. The impact of medical comorbidity on mental health and functional health outcomes among children with anxiety disorders. J Dev Behav Pediatr 2008;29:394-402.

18 Besser MJ, Ganor Y, Levite M. Dopamine by itself activates either D2, D3 or D1/D5 dopaminergic receptors in normal human T-cells and triggers the selective secretion of either IL-10, TNF-alpha or both. J Neuroimmunol 2005;169:161-71.

19 Buske-Kirschbaum A, Schmitt J, Plessow F, et al. Psychoendocrine and psychoneuroimmunological mechanisms in the comorbidity of atopic eczema and attention deficit/hyperactivity disorder. Psychoneuroendocrinology 2013;38:12-23.

20 Ulmer-Yaniv A, Djalovski A, Priel A, et al. Maternal depression alters stress and immune biomarkers in mother and child. Depress Anxiety 2018;35:1145-57.

21 Jerrell JM, Mclntyre RS, Tripathi A. A cohort study of the prevalence and impact of comorbid medical conditions in pediatric bipolar disorder. J Clin Psychiatry 2010;71:1518-25.

22 Reaume SV, Ferro MA. Chronicity of mental comorbidity in children with new-onset physical illness. Child Care Health Dev 2019;45:559-67.

23 Hilliard ME, Herzer M, Dolan LM, et al. Psychological screening in adolescents with type 1 diabetes predicts outcomes one year later. Diabetes Res Clin Pract 2011;94:39-44.

24 Ferro MA. Adolescents and young adults with physical illness: a comparative study of psychological distress. Acta Paediatr 2014;103:e32-7.

25 Ferro MA, Van Lieshout RJ, Scott JG, et al. Condition-specific associations of symptoms of depression and anxiety in adolescents 
and young adults with asthma and food allergy. J Asthma 2016;53:282-8.

26 Ferro MA, Boyle MH. Self-concept among children and adolescents with a chronic illness: a meta-analytic review. Health Psychol 2013;32:839-48.

27 Pinquart M, Shen Y. Behavior problems in children and adolescents with chronic physical illness: a meta-analysis. J Pediatr Psychol 2011;36:1003-16.

28 Jones LC, Mrug S, Elliott MN, et al. Chronic physical health conditions and emotional problems from early adolescence through midadolescence. Acad Pediatr 2017;17:649-55.

29 Boyle MH, Duncan L, Georgiades K, et al. Classifying child and adolescent psychiatric disorder by problem checklists and standardized interviews. Int J Methods Psychiatr Res 2017;26:e1544.

30 Duncan L, Georgiades K, Wang L, et al. Psychometric evaluation of the mini international neuropsychiatric interview for children and adolescents (MINI-KID). Psychol Assess 2018;30:916-28.

31 Qadeer RA, Ferro MA. Child-parent agreement on healthrelated quality of life in children with newly diagnosed chronic health conditions: a longitudinal study. Int $J$ Adolesc Youth 2018;23:99-108.

32 Ferro MA. Mediated moderation of the relation between maternal and adolescent depressive symptoms: role of adolescent physical health. Soc Psychiatry Psychiatr Epidemiol 2015;50:1743-51.

33 Ferro MA, Boyle MH. The impact of chronic physical illness, maternal depressive symptoms, family functioning, and self-esteem on symptoms of anxiety and depression in children. J Abnorm Child Psychol 2015;43:177-87

34 Kornelsen E, Buchan MC, Gonzalez A, et al. Hair cortisol concentration and mental disorder in children with chronic physical illness. Chronic Stress 2019;3.

35 Buchan MC. Hair cortisol concentration as a predictor of quality of life among children with mental disorder. Canada: University of Waterloo, 2019.

36 Ferro MA, Buchan MC, Gonzalez A. The role of hair cortisol concentration in the association between parent and child psychopathology: a sex-based analysis. Psychother Psychosom 2019;88:43.

37 He J-P, Paksarian D, Merikangas KR. Physical activity and mental disorder among adolescents in the United States. J Adolesc Health 2018;63:628-35.

38 Rodriguez-Ayllon M, Cadenas-Sánchez C, Estévez-López F, et al. Role of physical activity and sedentary behavior in the mental health of preschoolers, children and adolescents: a systematic review and meta-analysis. Sports Med 2019;49:1383-410.

39 Biddle SJH, Ciaccioni S, Thomas G, et al. Physical activity and mental health in children and adolescents: an updated review of reviews and an analysis of causality. Psychol Sport Exerc 2019;42:146-55.

40 Beauchamp MR, Puterman E, Lubans DR. Physical inactivity and mental health in late adolescence. JAMA Psychiatry 2018;75:543-4

41 Pascoe MC, Parker AG. Physical activity and exercise as a universal depression prevention in young people: a narrative review. Early Interv Psychiatry 2019;13:733-9.

42 Kamal NN, Ragy MM. The effects of exercise on C-reactive protein insulin, leptin and some cardiometabolic risk factors in Egyptian children with or without metabolic syndrome. Diabetol Metab Syndr 2012;4.

43 Martinez-Gomez D, Eisenmann JC, Wärnberg J, et al. Associations of physical activity, cardiorespiratory fitness and fatness with lowgrade inflammation in adolescents: the AFINOS study. Int $J$ Obes 2010;34:1501-7.

44 Nielsen MS, Quist JS, Chaput J-P, et al. Physical activity, sedentary time, and sleep and the association with inflammatory markers and adiponectin in 8- to 11-year-old Danish children. J Phys Act Health 2016;13:733-9.

45 Gandhi S, Chiu M, Lam K, et al. Mental health service use among children and youth in Ontario: population-based trends over time. Can J Psychiatry 2016;61:119-24.

46 Stein RE, Silver EJ. Operationalizing a conceptually based noncategorical definition: a first look at US children with chronic conditions. Arch Pediatr Adolesc Med 1999;153:68-74.

47 Cohen $\mathrm{E}$, Patel $\mathrm{H}$. Responding to the rising number of children living with complex chronic conditions. Can Med Assoc J 2014;186:1199-200.

48 Berry JG, Hall M, Neff J, et al. Children with medical complexity and Medicaid: spending and cost savings. Health Aff 2014;33:2199-206.

49 Cohen E, Berry JG, Camacho X, et al. Patterns and costs of health care use of children with medical complexity. Pediatrics 2012;130:e1463-70.
50 Speechley KN, Ferro MA, Camfield CS, et al. Quality of life in children with new-onset epilepsy: a 2-year prospective cohor study. Neurology 2012;79:1548-55.

51 Ferro MA, Avery L, Fayed N, et al. Child- and parent-reported quality of life trajectories in children with epilepsy: a prospective cohort study. Epilepsia 2017;58:1277-86.

52 Sheehan DV, Sheehan KH, Shytle RD, et al. Reliability and validity of the mini international neuropsychiatric interview for children and adolescents (MINI-KID). J Clin Psychiatry 2010;71:313-26.

53 Georgiades K, Duncan L, Wang L, et al. Six-Month prevalence of mental disorders and service contacts among children and youth in Ontario: evidence from the 2014 Ontario child health study. Can J Psychiatry 2019;64:246-55.

54 Polanczyk GV, Salum GA, Sugaya LS, et al. Annual research review: a meta-analysis of the worldwide prevalence of mental disorders in children and adolescents. J Child Psychol Psychiatry 2015;56:345-65.

55 Boyle MH, Duncan L, Georgiades K, et al. The 2014 Ontario Child Health Study Emotional Behavioural Scales (OCHS-EBS) Part II: Psychometric Adequacy for Categorical Measurement of Selected DSM-5 Disorders. Can J Psychiatry 2019;64:434-42.

56 Duncan L, Georgiades K, Wang L, et al. The 2014 Ontario Child Health Study Emotional Behavioural Scales (OCHS-EBS) Part I: A Checklist for Dimensional Measurement of Selected DSM-5 Disorders. Can J Psychiatry 2019;64:423-33.

57 Kim J-W, Szigethy EM, Melhem NM, et al. Inflammatory markers and the pathogenesis of pediatric depression and suicide: a systematic review of the literature. J Clin Psychiatry 2014;75:1242-53

58 Salim S, Chugh G, Asghar M. Inflammation in anxiety. Adv Protein Chem Struct Biol 2012;88:1-25.

59 Li G, Bauer S, Nowak M, et al. Cytokines and epilepsy. Seizure 2011;20:249-56.

60 Mehra VC, Ramgolam VS, Bender JR. Cytokines and cardiovascular disease. J Leukoc Biol 2005;78:805-18.

61 Neurath MF. Cytokines in inflammatory bowel disease. Nat Rev Immunol 2014;14:329-42.

62 McDade TW. Development and validation of assay protocols for use with dried blood spot samples. Am J Hum Biol 2014;26:1-9.

63 Miller GE, Chen E, Zhou ES. If it goes up, must it come down? chronic stress and the hypothalamic-pituitary-adrenocortical axis in humans. Psychol Bull 2007;133:25-45.

64 Short SJ, Stalder T, Marceau K, et al. Correspondence between hair cortisol concentrations and 30-day integrated daily salivary and Weekly urinary cortisol measures. Psychoneuroendocrinology 2016;71:12-18.

65 Bates R, Salsberry P, Ford J. Measuring stress in young children using hair cortisol: the state of the science. Biol Res Nurs 2017;19:499-510.

66 Meyer JS, Novak MA. Minireview: hair cortisol: a novel biomarker of hypothalamic-pituitary-adrenocortical activity. Endocrinology 2012;153:4120-7.

67 Staufenbiel SM, Penninx BWJH, de Rijke YB, et al. Determinants of hair cortisol and hair cortisone concentrations in adults. Psychoneuroendocrinology 2015;60:182-94.

68 Wosu AC, Valdimarsdóttir U, Shields AE, et al. Correlates of cortiso in human hair: implications for epidemiologic studies on health effects of chronic stress. Ann Epidemiol 2013;23:797-811.

69 Gibson EL, Checkley S, Papadopoulos A, et al. Increased salivary cortisol reliably induced by a protein-rich midday meal. Psychosom Med 1999;61:214-24.

70 Adam EK, Hawkley LC, Kudielka BM, et al. Day-to-day dynamics of experience--cortisol associations in a population-based sample of older adults. Proc Natl Acad Sci U S A 2006;103:17058-63.

71 Feller S, Vigl M, Bergmann MM, et al. Predictors of hair cortisol concentrations in older adults. Psychoneuroendocrinology 2014;39:132-40.

72 Smy L, Shaw K, Smith A, et al. Hair cortisol as a novel biomarker of HPA suppression by inhaled corticosteroids in children. Pediatr Res 2015;78:44-7.

73 Folio MR, Fewell RR. Peabody developmental motor scales: examiner's manual. Austin: Pro-ed, 2000.

74 Wang H-H, Liao H-F, Hsieh C-L. Reliability, sensitivity to change, and responsiveness of the peabody developmental motor scales-second edition for children with cerebral palsy. Phys Ther 2006;86:1351-9.

75 Takken T, Stephens S, Balemans A, et al. Validation of the Actiheart activity monitor for measurement of activity energy expenditure in children and adolescents with chronic disease. Eur J Clin Nutr 2010;64:1494-500. 
76 Trost SG, Pate RR, Freedson PS, et al. Using objective physical activity measures with youth: how many days of monitoring are needed? Med Sci Sports Exerc 2000;32:426-31.

77 Delisle Nyström C, Pomeroy J, Henriksson P, et al. Evaluation of the wrist-worn ActiGraph wGT3x-BT for estimating activity energy expenditure in preschool children. Eur J Clin Nutr 2017;71:1212-7.

78 Zhang Z, Wang L. Statistical power analysis for growth curve models using SAS. Behav Res Methods 2009;41:1083-94.

79 Thoemmes F, Mackinnon DP, Reiser MR. Power analysis for complex mediational designs using Monte Carlo methods. Struct Equ Modeling 2010;17:510-34.

80 Tabachnick BG, Fidell LS. Using multivariate statistics. 5th ed. Boston: Pearson, 2006.

81 Kline RB. Principles and practice of structural equation modeling. 4Th. New York: The Guilford Press, 2016.

82 Purcell R, Jorm AF, Hickie IB, et al. Demographic and clinical characteristics of young people seeking help at youth mental health services: baseline findings of the transitions study. Early Interv Psychiatry 2015;9:487-97.

83 Georgiades K, Boylan K, Duncan L, et al. Prevalence and correlates of youth suicidal ideation and attempts: evidence from the 2014 Ontario child health study. Can J Psychiatry 2019;64:265-74.

84 Dillman DA, Smyth JD, Internet CLM. Mail, and mixed-mode surveys: the tailored design method. New Jersey: John Wiley \& Sons, 2009.

85 Graham JW. Missing data analysis: making it work in the real world. Annu Rev Psychol 2009;60:549-76.

86 Ferro MA. Missing data in longitudinal studies: cross-sectional multiple imputation provides similar estimates to full-information maximum likelihood. Ann Epidemiol 2014;24:75-7.

87 Goodman R. Psychometric properties of the Strengths and Difficulties Questionnaire. Journal of the American Academy of Child \& Adolescent Psychiatry 2001;40:1337-45.

88 Ravens-Sieberer U, Herdman M, Devine J, et al. The European KIDSCREEN approach to measure quality of life and well-being in children: development, current application, and future advances. Qual Life Res 2014;23:791-803.

89 Marsh HW, Questionnaire SD. SDQ) I: a theoretical and empirical basis for the measurement of multiple dimensions of preadolescent self-concept. An interim test manual and research monograph. University of Western Sydney: Macarthur, 1992.
90 Ferro MA, Boyle MH. Longitudinal invariance of measurement and structure of global self-concept: a population-based study examining trajectories among adolescents with and without chronic illness. J Pediatr Psychol 2013;38:425-37.

91 Harter S. The Perceived Competence Scale for Children. Child Dev 1982;53:87-97.

92 Ferro MA, Tang J. Psychometric properties of the Self-Perception Profile for Children in children with chronic illness. J Can Acad Child Adolesc Psychiatry 2017;26:119-24.

93 Üstün TB, Kostanjsek N, Chatterji S, et al. Measuring health and disability: manual for WHO Disability Assessment Schedule: WHODAS 2.0. Geneva: World Health Organization, 2010.

94 Tompke BK, Tang J, Oltean II, et al. Measurement invariance of the WHODAS 2.0 across youth with and without physical or mental conditions. Assessment 2018;43:107319111881643.

95 Bain SK, Jaspers KE. Kaufman brief intelligence test, 2nd edition. J Psychoeduc Assess 2010;28:167-74.

96 Radloff LS. The CES-D scale: a self-report depression scale for research in the general population. Appl Psychol Meas 1977;1:385-401.

97 Spitzer RL, Kroenke K, Williams JBW, et al. A brief measure for assessing generalized anxiety disorder. Arch Intern Med 2006;166:1092-7.

98 Ware JE, Snow KK, Kosinski M, et al. SF-36 health survey manual and interpretation guide. Boston: New England Medical Center, The Health Institute, 1993.

99 Byles J, Byrne C, Boyle MH, et al. Ontario Child Health Study: reliability and validity of the General Functioning subscale of the McMaster Family Assessment Device. Fam Process 1988;27:97-104.

100 Epstein NB, Baldwin LM, Bishop DS. The McMaster Family Assessment Device. J Marital Fam Ther 1983;9:171-80.

101 Berry JO, Jones WH. The Parental Stress Scale: initial psychometric evidence. J Soc Pers Relat 1995;12:463-72.

102 Zelman JJ, Ferro MA. Psychometric properties of the parental stress scale in families of children with chronic physical conditions. Fam Relations 2018:67:240-52.

103 Daniels D, Plomin R. Differential experience of siblings in the same family. Dev Psychol 1985;21:747-60.

104 Boyle MH, Georgiades K, Duncan L, et al. The 2014 Ontario Child Health Study-Methodology. Can J Psychiatry 2019;64:237-45. 